\title{
Residential Chemistry Camps for School Students: Why Bother?
}

\section{T.G. Harrison, S.J. Croker \& D.E. Shallcross}

School of Chemistry, University of Bristol, Cantock's Close, Bristol BS8 1TS, UK

\section{Corresponding author:}

Tim Harrison, School of Chemistry, University of Bristol, Cantock's Close, Bristol BS8 1TS, UK

Email: t.g.harrison@bristol.ac.uk

\begin{abstract}
Bristol ChemLabS has been providing several residential school experiences per year for the past eight years. The Chemistry Camps are two days of intensive activity and, wherever possible, involve a stay in a hall of residence. The majority of the time is spent in undergraduate teaching laboratories learning new skills on the first day, which are then used again on the second. The other academic sessions include spectroscopy tours, short lectures from postgraduate students on their research areas, a discussion of university application procedures in general by admissions officers and a lecture demonstration. The non-academic side is also addressed via a stay in a hall of residence and a course dinner. The purpose of this paper is to discuss the organisation and running of such camps and to explore the benefits for both the students and the School of Chemistry.
\end{abstract}

Keywords: chemistry camps, residential courses, outreach

\section{Introduction}

The School of Chemistry at the University of Bristol has a large, self-sustaining outreach project (Harrison \& Shallcross 2010a,b, Harrison et al. 2011c, Shallcross et al. 2013). Part of the portfolio of outreach events includes residential stays organised through Bristol ChemLabS. These take place at times when the undergraduates are not using the teaching laboratories, typically around Easter, June and July. There is a variety of audiences for these activities ranging from individual students to UK and international school parties. 
Table 1 Responses to the question 'Which subjects will you be applying to university to study?'

\begin{tabular}{lc} 
Subjects & $\begin{array}{c}\text { Numbers of } \\
\text { Students }\end{array}$ \\
Chemistry & 24 \\
Biochemical Engineering & 1 \\
Biochemistry & 6 \\
Biology & 1 \\
Biomed Science & 1 \\
Cellular Medicine & 1 \\
Chemical Engineering & 1 \\
Dentistry & 1 \\
Engineering & 1 \\
English Language & 1 \\
Mathematics & 1 \\
Medicine & 10 \\
Natural Science & 2 \\
Pharmaceutical Science / & 5 \\
Pharmacology & 1 \\
Photography & 1 \\
Physics & 1 \\
Psychology & 1 \\
Religious Studies & 1 \\
Virology and Immunology & 1 \\
\hline
\end{tabular}

There are several possible reasons for running such courses:

- to assist school students in making informed choices about whether Chemistry degree courses, or indeed Higher Education generally, is for them;

- to promote the host university (Shaw et al. 2011);

- to promote the subject, whether regionally, nationally or internationally (Shallcross \& Harrison 2007, Harrison et al. 2011a);

- to develop the soft skills of the university students involved in outreach activities (Hanson \& Overton 2010, Harrison et al. 2011b);

- $\quad$ to meet research grant 'impact' targets;

- to fulfil a desire to support secondary teachers (Shaw et al. 2010).

In the UK, universities are charged by the Office for Fair Access (OFFA) (see http://www.offa.org.uk) with providing university engagement activities for students who are non-traditional university applicants such as those from underperforming state schools, from families with no history of higher education participation, disabled students, targeted ethnic minorities, and those from single-parent families, in the light of the challenges of raised tuition fees (Ross \& Lloyd 2013).

\section{Halls of residence experience}

\author{
"The student's accommodation is \\ very basic!"
}

A major part of an undergraduate's first year at university in many Higher Education Institutions revolves around a hall of residence. School students have little idea of what living in a hall is like so wherever possible a stay in one should be part of the experience. The halls also give rise to additional opportunities to socialise as well as to explore hall facilities. Residential stays do give rise to additional problems of supervision since the students are under 18 years of age. When working with a school group the accompanying teachers take responsibility. When school students do not have teachers present, representatives from Bristol ChemLabS Outreach will also stay in the halls. Those present will have been through STEM Ambassador training and will have had the appropriate police checks. For mixed gender groups there will be both male and female representatives. Depending on the hall of residences used the groups will be split across different floors or areas of the accommodation. This is particularly important to make clear where young girls from different cultural groups are to be present.

\section{The programme}

Practical work is a major component of the experience. It has been found that school students tend to be intimidated by large teaching laboratories. For this reason students are paired for practical work with pairings changed for each session. Before any practical work is undertaken the health and safety requirements of working in the teaching laboratories are explained, and correctly sized lab coats and safety glasses are distributed.

The initial practical task is always short, relatively straight-forward and relatively amusing. The main purpose is to get the students to feel comfortable in the lab with an understanding of where 'stuff' is kept, how chemicals are to be measured and disposed of, and of other common lab procedures. A competition involving the iodine clock reaction is one such practical task.

The remaining tasks on the first day are chosen to teach practical skills that can be used on the second day. The second practical task is to create a calibration curve for a transition metal salt using UV-visible spectrophotometry. Students are given oral instructions only and are presented with 
volume measuring apparatus and a solution of known concentration. Students were expected to accurately dilute the known concentration and were then shown how to use the spectrometer. The resulting graph is then used to determine the concentration of the unknown solution. At the end of the task the unknown concentration value is given for the students to judge their skills. The afternoon session first sees the students digesting their lunch whilst taking part in a lecture demonstration involving liquid nitrogen, hydrogen balloon explosions, dry ice and humour. The last practical of the day has the students extracting caffeine from tea leaves. This practical introduces most students to heating with a hotplate, Buchner filtration, cooling via ice baths, solvent extraction and separating funnel use, rotary evaporation, infrared spectroscopy and melting point apparatus.

The first day's academic session ends with a lecture by a postgraduate. After settling into the halls of residence the entire group, complete with some postgraduate demonstrators, then retires to a local restaurant for the course dinner. This allows more informal and valuable time for the students to mix with each other and to talk to the postgraduates and lab staff.

The second day starts with a tour of several analytical and spectroscopic techniques laboratories in support of the content met, or to be met, in Post 16 Chemistry (Harrison et al. 2010). These typically include Nuclear Magnetic Resonance (NMR), Mass Spectrometry (MS), Scanning Electron Microscopy (SEM) and Gas Chromatography Mass Spectrometry (GCMS). The talks are usually given by specialist technicians or postgraduates. The major practical element of the day, an extended synthesis with elements of analysis added, uses many of the practical techniques learned on the previous day so the students can take more ownership of the lab tasks.

The camp finishes with talks. A last 30-minute lecture by a postgraduate is followed by a session on the university application process given by colleagues engaged in this task. The short presentation allows for numerous Q\&A. Having the session at the end of the course allows time for the group to gel and so there is little reticence in asking meaningful questions. Table 2 categorises the feedback of students' perceptions of the best elements of a Chemistry Camp.

\section{Postgraduate involvement}

The lectures given by the postgraduates are talks that have been developed with the School Teacher Fellow (Shallcross \& Harrison 2007a,b) so that they are at the correct level of communication for the
Table 2 Categories of feedback comments in response to the question 'What aspects of the summer camp did you enjoy the most?'

\begin{tabular}{lc} 
Topic & Numbers of comments \\
Experiments & 22 \\
Halls of Residence & 8 \\
Lecture Demonstrations & 8 \\
UCAS Talk & 6 \\
Social Side & 5 \\
'Everything' & 3 \\
Analytical Tours & 2 \\
Hospitality & 2 \\
Use of Equipment & 2 \\
Confidence Building & 1 \\
Independence & 1 \\
Talks & 1 \\
\hline
\end{tabular}

audience or broaden the school science and cover topics of interest, e.g. the Mesoamerican alcoholic drink 'pulque'; assessing climate change in interglacial ice ages; the Chemistry of toothpaste; and fragrance Chemistry.

Trained postgraduates acting as demonstrators are a vital component of the experience. They make excellent role models and are much nearer the school students' in age than the average academic or lab technician.

Both teams of postgraduates enjoy their informal teaching experiences and get a lot out of them Harrison et al. (2011a).

\section{Eating arrangements}

Supplying such large groups of students with meals and refreshments is an important consideration.

The morning and afternoon coffee breaks with hot and cold drinks plus chocolate biscuits are needed to allow valuable informal time for the students to engage with their postgraduate demonstrators and with staff. Lunches depend on location. At Bristol we have the option of organising packed lunches for course attendees or allowing them to source their own lunches from the nearby sandwich bars and restaurants.

\section{Why do school students want to attend chemistry camps?}

Many reasons are given. Ideally students attend because they wish to experience what it would be like to be a Chemical Sciences undergraduate. Others use the experience to fulfil their school's 'work experience' demands. Gaining work 


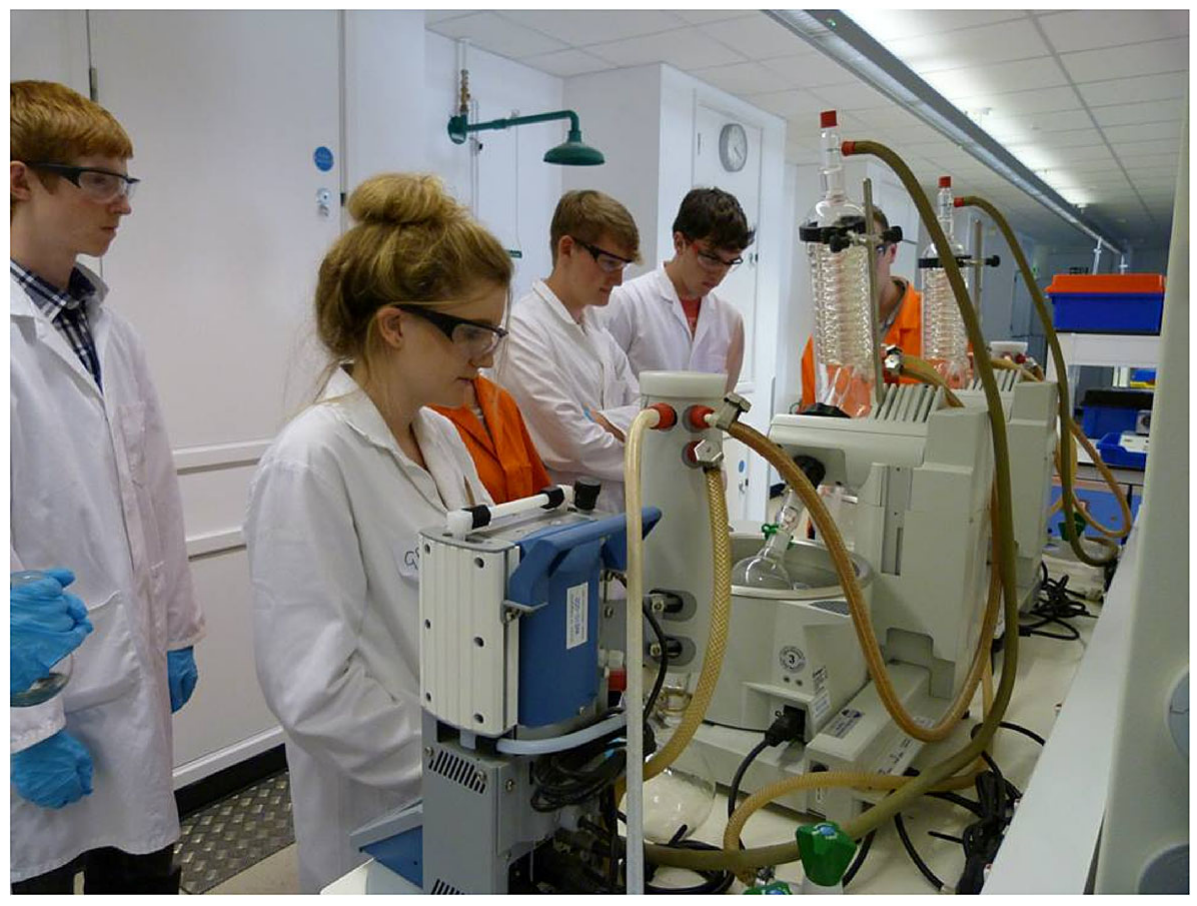

Figure 1 Students doing lab work during summer school.

experience in the chemical industry is not as easy in some parts of the UK as in others. Some students use the opportunity to have something to talk about on their university application forms and at subsequent interviews. Often students considering studying Medicine and Medical Science degrees, and whether to take pre-university Chemistry courses, may attend such courses for all these reasons. Table 1 gives the degree subjects being considered by students attending 2 two-day Chemistry Camps in July 2013. It should be noted that several students did not give responses (as is their ethical right) while others gave multiple possibilities.

\section{What do students gain from chemistry camps?}

Academics often seem to believe that young people applying to university somehow know what they are letting themselves in for. University open days do go some way to showing prospective undergraduates what the fabric of the institution is like, but a residential stay allows the student to immerse him- or herself in the student experience and envisage what it is like to be a science undergraduate. Their feedback indicates this is so:

"There is a lot more freedom lots of work, especially independent study."

"I've learnt that you are put into situations where you have to socialise and therefore it will benefit your confidence in mixing with new people."

"Greater level of independence required [than school] ... [The need] to think about practical work more instead of blindly following instructions."

"It's a very social environment and I can't wait for it."

Feedback from teachers who sent their students demonstrates the impact. One teacher wrote: "I just wanted to say a big thank you for the chem camp. One of my students came in and told me it was amazing and absolutely loved it and was bursting with excitement!" and that teacher-student debriefing was during the summer vacation!

Not all the feedback from students is positive. When asked what were their least favourite parts of the camp, comments such as having to climb stairs, the distance to walk to the hall of residence and "Having to constantly wash our hands" featured. The single largest area of elicited responses related to the spectroscopy tours; these responses were from Year 11 students who may not have appreciated the full relevance for their future studies.

\section{The advertising of chemistry camps}

Finding suitable delegates is not as easy as it might seem. Some universities will have locally based target schools. Bristol ChemLabS has a 
network of Chemistry teachers to whom it sends regular e-newsletters that can be used to advertise these events. It also has good contacts with a number of education authorities and science advisors, all with their own information distribution networks. Course information is also to be found on the outreach website (www.chemlabs.bris.ac.uk/outreach/).

Where specific categories of student are 'required', an application form that requires the student to give reasons for applying and a supporting reference from their Chemistry teacher is requested. The other information needed will include any information about medical conditions, dietary needs, parental permissions and emergency contact details.

\section{Funding}

Finding funding for such activities is always a challenge. Occasionally grants are available from within individual universities, associated industry or professional bodies. Some of Bristol's residential camps are funded by individual students, their schools or a mixture of both at full economic costing. Some schools can access their own grants to make these events possible, for example for 'gifted and talented' students. Bristol ChemLabS experience shows that the number of last-minute drop outs, sometimes for spurious reasons, decreases in line with the students' own increased financial commitment.

The level of administration required to create, deliver and follow up Chemistry Camps should not be underestimated and needs to be cost appropriately. Dealing with individual students rather than school parties is even more administratively challenging. Administration challenges aside, running two or three back-to-back two-day courses does not require much more additional effort than running one as far as organising lab technicians and speakers is concerned.

\section{Conclusions}

Well-funded and well-organised residential Chemistry Camps are of considerable value to institutions, school students and participating university students. Once they have been created and resourced they can be run time and time again. The students can gain insight into many areas of the undergraduate Chemistry student's life, some of which are not immediately obvious when setting up these events. Time taken to organise the invitation of individual students should not be underestimated. Once a programme for one camp has been trialled and revised subsequent and multiple camps can take place with little additional input.

"I have built so much confidence in the labs in the past few days. Amazing program!"

\section{Acknowledgements}

The authors thank Hefce for the Bristol ChemLabS CETL project within which the early developmental work of the outreach programme took place. D.E. Shallcross also wishes to thank the HEA for a National Teaching Fellowship.

\section{References}

Hanson, S. and Overton, T. (2010) Skills Required by New Chemistry Graduates and their Development in Degree Programmes, Higher Education Academy UK Physical Sciences Centre.

Harrison, T.G. and Shallcross, D.E. (2010a) Towards sustainable public engagement (Outreach), New Directions in the Teaching of Physical Sciences $\mathbf{6}$, 41-46.

Harrison, T.G. and Shallcross, D.E. (2010b) What should be expected of successful engagement between schools, colleges and universities? School Science Review 91 (35), 97-102.

Harrison, T.G., Shaw, A.J., Shallcross, K.L., Williams, S.J. and Shallcross, D.E. (2010) School-university partnerships: Lessons learned from 10 years of spectroscopy for teachers and post-16 students, New Directions in the Teaching of Physical Sciences $\mathbf{6}$, 72-76.

Harrison, T.G., Hanford, K.L., Cheesman, B.T., Kaur, G., Franklin, S.D., Laurain, A.M.C., Medley, M.I., Rivett, A.C., Sellou, L., Shallcross, K.L., Shaw, K.E., Williams, S.J. and Shallcross, D.E. (2011a) The many positive impacts of participating in outreach activities on postgraduate students, New Directions in the Teaching of Physical Sciences 7, 13-18.

Harrison, T.G., Shallcross, D.E., Norman, N.C., Sewry, J.D. and Davies-Coleman, M.T. (2011b) Publicising chemistry in a multicultural society through chemistry outreach, South African Journal 
of Science 107 (11/12), Art. \#669, 6 pages. doi:10.4102/sajs.v107i11/12.669.

Harrison, T.G., Shallcross, D.E. and Davey, W.D. (2011c) Making better and wider use of undergraduate teaching laboratories in the support of chemistry in the UK, New Directions in the Teaching of Physical Sciences 7, 79-84.

Ross, A. and Lloyd, J. (2013) Access for All. An investigation of young people's attitudes to the cost of higher education using the Longitudinal Study of Young People in England. London: Strategic Society Centre.

Shallcross, D.E. and Harrison, T.G. (2007a) A secondary school teacher fellow within a university chemistry department: The answer to problems of recruitment and transition from secondary school to university and subsequent retention? Chemistry Education Research and Practice 8, 101-104.
Shallcross, D.E. and Harrison, T.G. (2007b) The impact of School Teacher Fellows on teaching and assessment at tertiary level. New Directions 3, 77-78.

Shallcross, D.E., Harrison, T.G., Obey, T.M., Croker, S.J. and Norman, N.C. (2013) Outreach within the Bristol ChemLabS CETL (Centre for Excellence in Teaching and Learning), Higher Education Studies 3, 39-49.

Shaw, A.J., Harrison , T.G. and Shallcross, D.E. (2010) What value has chemistry outreach by a university department to secondary schools? Teacher perceptions of Bristol ChemLabS outreach events, Acta Didactica Napocensia 3 (3), 15-23.

Shaw, A.J., Harrison, T.G., Shallcross, K.L., Williams, S.J. and Shallcross, D.E. (2011) On the impact of the Bristol ChemLabS' Outreach program on admissions to the School of Chemistry, New Directions in the Teaching of Physical Sciences 7, 22-26. 